http://jmscr.igmpublication.org/home/

ISSN (e)-2347-176x ISSN (p) 2455-0450

crossref DOI: https://dx.doi.org/10.18535/jmscr/v8i6.101

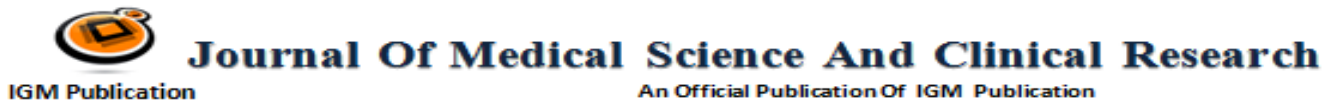

\title{
A study of the effect of ambient temperature on mortality rate of burns patients
}

\author{
Authors \\ Dr R.Bhavani Rao, Dr Shalini Duvvada \\ Dr.NTRUHS
}

\section{Introduction}

Fire, man's first double-edged sword, throughout history has both served as a good servant being a loyal guardian and also has destroyed mankind like a brutal enemy. Ever since man invented fire, he has found a way to burn himself and since then began his search of ways to treat burns. Every year there are about 7-8 lakh hospital admissions with burns in India as compared to about 13,000 in the UK and 40,000 in U.S.A. As more than $1,20,000$ deaths occur due to burns injury every year in India. The incidence of deaths due to burns in India is unfortunately high \& many factors are responsible for this. Important among them being widespread illiteracy, poverty, over-crowding, unemployment, lack of adequate healthcare facilities and social and emotional factors. Death due to burns is surprisingly very high, next only to RTA. ${ }^{[1]}$

In this Study we have compared various temperatures at which deaths are occurring in Mixed Thermal Burns in Government General Hospital, Guntur \& is an Observational study only.

\section{Objectives of the Study}

1. To Study the effect of Ambient \& Real Feel Temperature over the Mortality rate of burns patients in Government General Hospital, Guntur.

2. To Study various temperatures at which increased Mortality rate is seen in Burns patients in Government General Hospital, Guntur.

The material for the Study of Effect of Temperature on Mortality Rate was collected from burns cases admitted to various General surgical wards in Guntur medical college and hospital, Guntur; during the period from January 2017 to December 2018. A total of fifty cases of Death due to Mixed Thermal Burns were included in the study after obtaining clearance from the ethical committee

\section{Inclusion Criteria}

1. All deaths of Mixed Thermal Burns aged more than 12 years of age who are admitted in Government General Hospital, Guntur

2. All deaths due to Mixed Thermal Burns $40-80 \%$ TBSA who are admitted in Government General Hospital, Guntur

3. All deaths of Mixed Thermal burns happened after $72 \mathrm{hrs}$ of admission in Government General Hospital, Guntur 


\section{Exclusion Criteria}

1. All deaths of Mixed Thermal Burns aged less than 12 years of age who are admitted in Government General Hospital, Guntur

2. All deaths due to Mixed Thermal Burns less than 40\% TBSA who are admitted in Government General Hospital, Guntur

3. All deaths due to Mixed Thermal Burns more than $80 \%$ TBSA who are admitted in Government General Hospital, Guntur

4. All deaths of Mixed Thermal burns happened before $72 \mathrm{hrs}$ of admission in Government General Hospital, Guntur

All patients were assessed clinically as to

- \% body surface area involvement - using Rule of Nine chart

- The degree of burns

- Mode of treatment

The initial evaluation and procedures on admission to the Burn Unit were the same in all 50 patients. Urgent life-threatening respiratory and/or cardiac emergency were managed first. Vital signs were measured and charted. Intravenous catheter was inserted, blood for laboratory tests was withdrawn, and intravenous resuscitation fluids were started. The burn size in total body surface area (TBSA) and the severity of burned areas was determined by clinical assessment. Patients with burns of more than $20 \%$ TBSA were catheterized and urine output was measured. A personal and family medical history was recorded. A physical examination was performed. Bathing or cleaning of contaminated burns was done. Fluid intake, output volumes and were charted and evaluated.

Case section was done basis on the \% of TBSA, age of the patient, manner of burns and concomitant illness. Soon after the admission, clinical data were recorded according to the Proforma.

The investigations done in the cases for study were:-

1. Blood Routine tests including haemoglobin percentage, blood grouping and typing, WBC count and differential count, ESR and blood urea, serum creatinine, serum electrolytes.

2. Urine Routine examination, albumin, sugar and microscopy.

3. Plain chest x-ray, ECG also done.

Immediately after the admission along with above procedure resuscitation with IV fluids according to Parkland formula till the hydration and urine output becomes normal. Nasogastric decompression with Ryles tube carried out and antibiotic prophylaxis started. And close observation of all bedside parameters (like pulse rate, BP, Urine output was done.

Statistical Methods: Chi-square and Fisher Exact test has been used to find the Effect of The Ambient and The Real Feel temperature on the mortality rate in Burns patients.

\section{Chi-Square Test}

$$
\chi^{2}=\frac{\sum(O i-E i)^{2}}{E i}
$$

Where $\mathrm{Oi}$ is observed frequency and Eiis Expected frequency

\section{Fisher Exact Test}

\begin{tabular}{|l|c|c|c|}
\hline & Class 1 & Class 2 & Total \\
\hline Sample 1 & A & B & $\mathrm{a}+\mathrm{b}$ \\
\hline Sample 2 & C & D & $\mathrm{c}+\mathrm{d}$ \\
\hline Total & $\mathrm{a}+\mathrm{c}$ & $\mathrm{b}+\mathrm{d}$ & $\mathrm{N}$ \\
\hline
\end{tabular}

Fisher Exact Test statistic

$$
=\sum p=\frac{(a+b) !(c+d) !(a+c) !(b+d) !}{n !} \frac{1}{\sum a ! b ! c ! d}
$$

3. Odds Ratio: $\mathrm{OR}=\mathrm{ad} / \mathrm{bc}$

\section{Statistical software}

The Statistical software namely SPSS 11.0 and Systat 8.0 were used for the analysis of the data and Microsoft word and Excel have been used to generate graphs, tables etc.

\section{Results}

The study of 50 cases of Mixed Thermal Burn Deaths \& Relation with environmental temperature is carried out between January 2017 to December 2018

At Government General Hospital, Guntur and the results as follow 
Table 1 Age \& Sex Distribution of Burns

\begin{tabular}{|l|c|c|c|}
\hline Age in Years & Male & Female & Total \\
\hline $12-20$ & 0 & $4(12.5)$ & $4(8)$ \\
\hline $21-30$ & $7(38.9)$ & $15(46.9)$ & $22(44)$ \\
\hline $31-40$ & $8(44.4)$ & $4(12.5)$ & $12(24)$ \\
\hline $41-50$ & $3(16.7)$ & $2(6.2)$ & $5(10)$ \\
\hline $51-60$ & 0 & $1(3.1)$ & $1(2)$ \\
\hline $61-70$ & 0 & $5(15.7)$ & $5(10)$ \\
\hline$>70$ & 0 & $1(3.1)$ & $1(2)$ \\
\hline & $18(100)$ & $32(100)$ & $50(100)$ \\
\hline
\end{tabular}
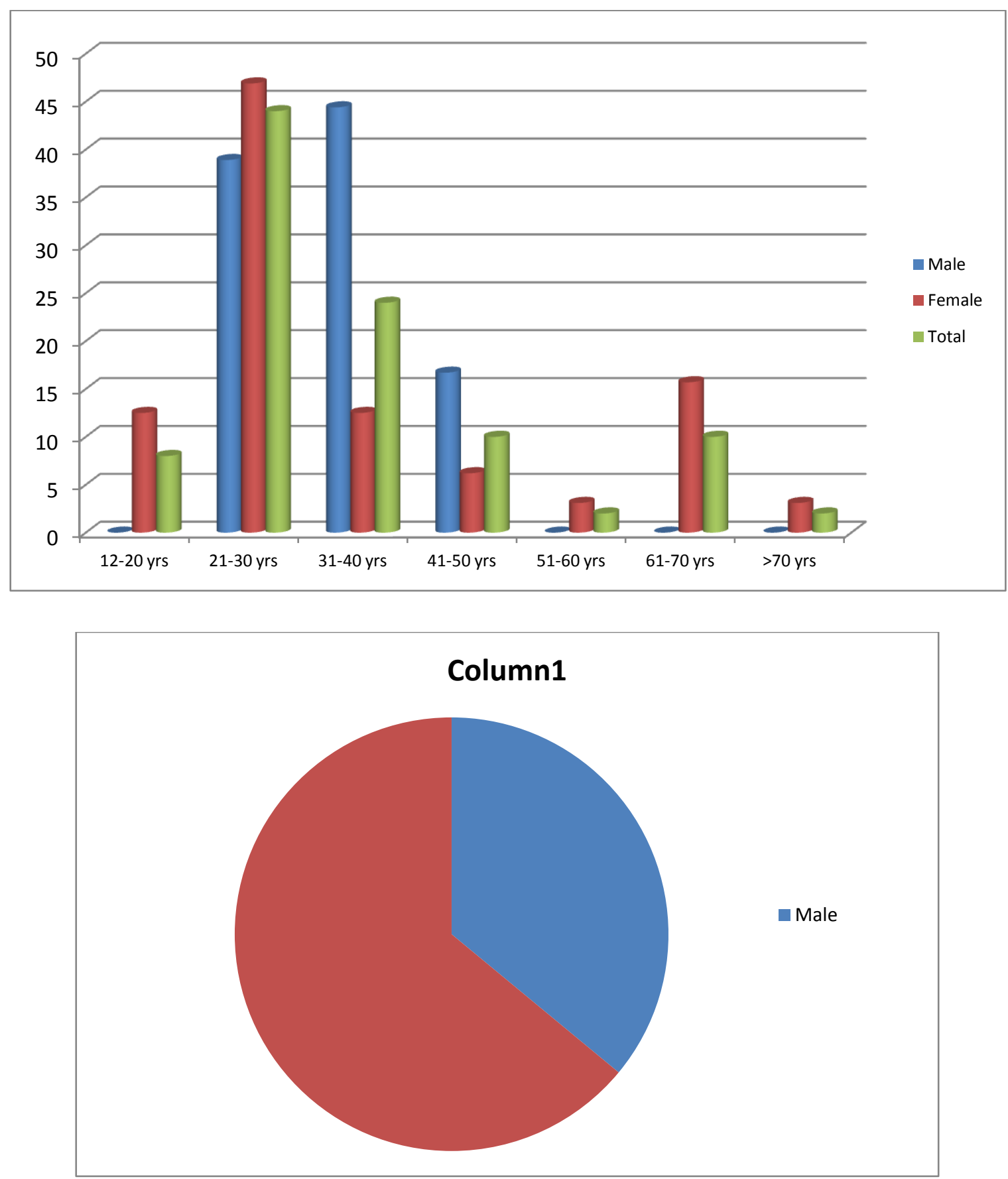

Fig 1 Sex Distribution of Burns 
Table 2 Distribution of Percentage of Burns

\begin{tabular}{|l|c|c|c|}
\hline Percentage of Burns & Male & Female & Total \\
\hline $40-45 \%$ & 1 & 0 & 1 \\
\hline $45-50 \%$ & 0 & 5 & 5 \\
\hline $50-55 \%$ & 0 & 2 & 2 \\
\hline $55-60 \%$ & 2 & 7 & 9 \\
\hline $60-65 \%$ & 4 & 1 & 5 \\
\hline $65-70 \%$ & 1 & 2 & 3 \\
\hline $70-75 \%$ & 2 & 6 & 8 \\
\hline $75-80 \%$ & 8 & 9 & 17 \\
\hline Total & 18 & 32 & 50 \\
\hline
\end{tabular}

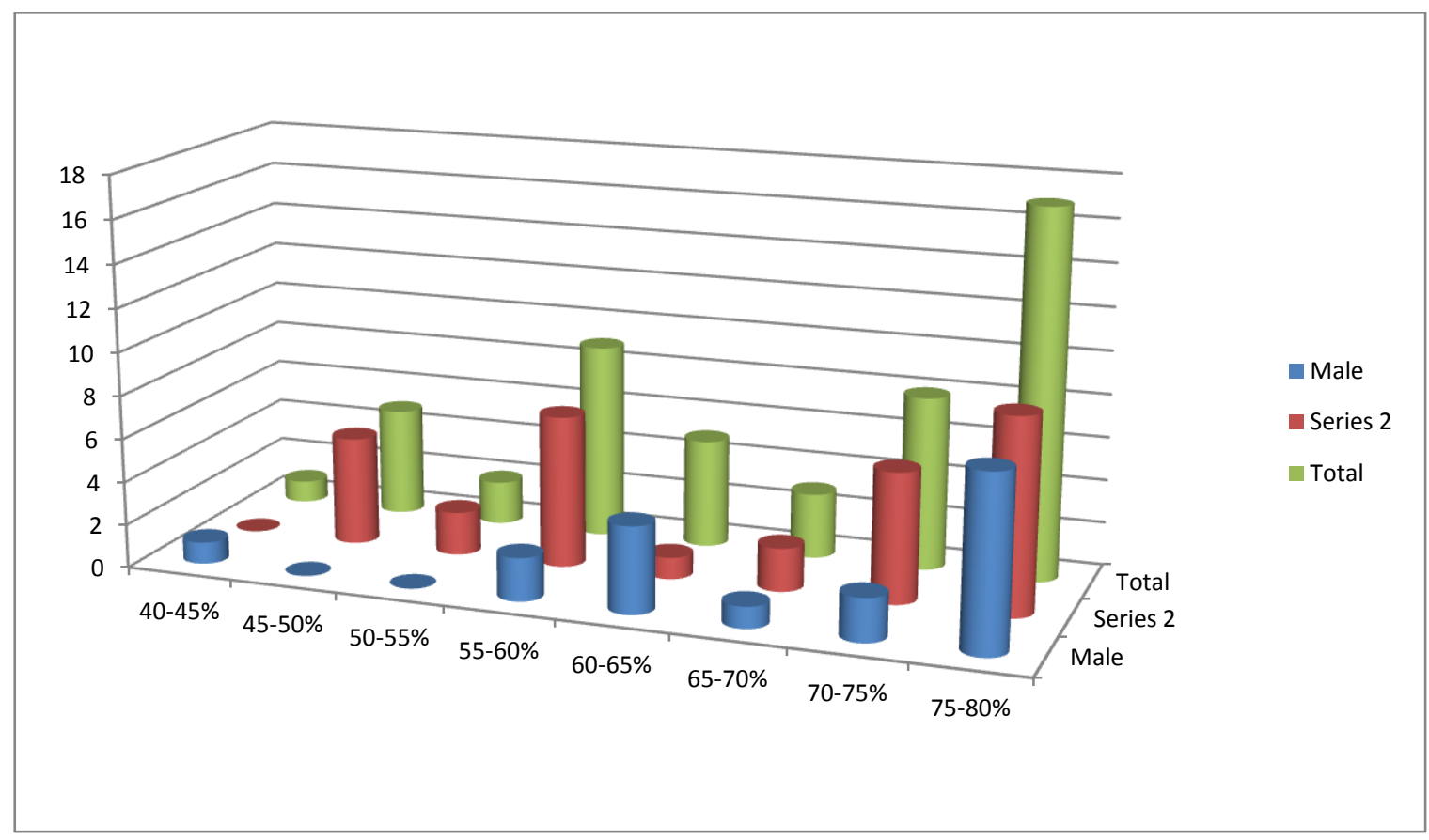

Fig 2 Distribution of Percentage of Burns

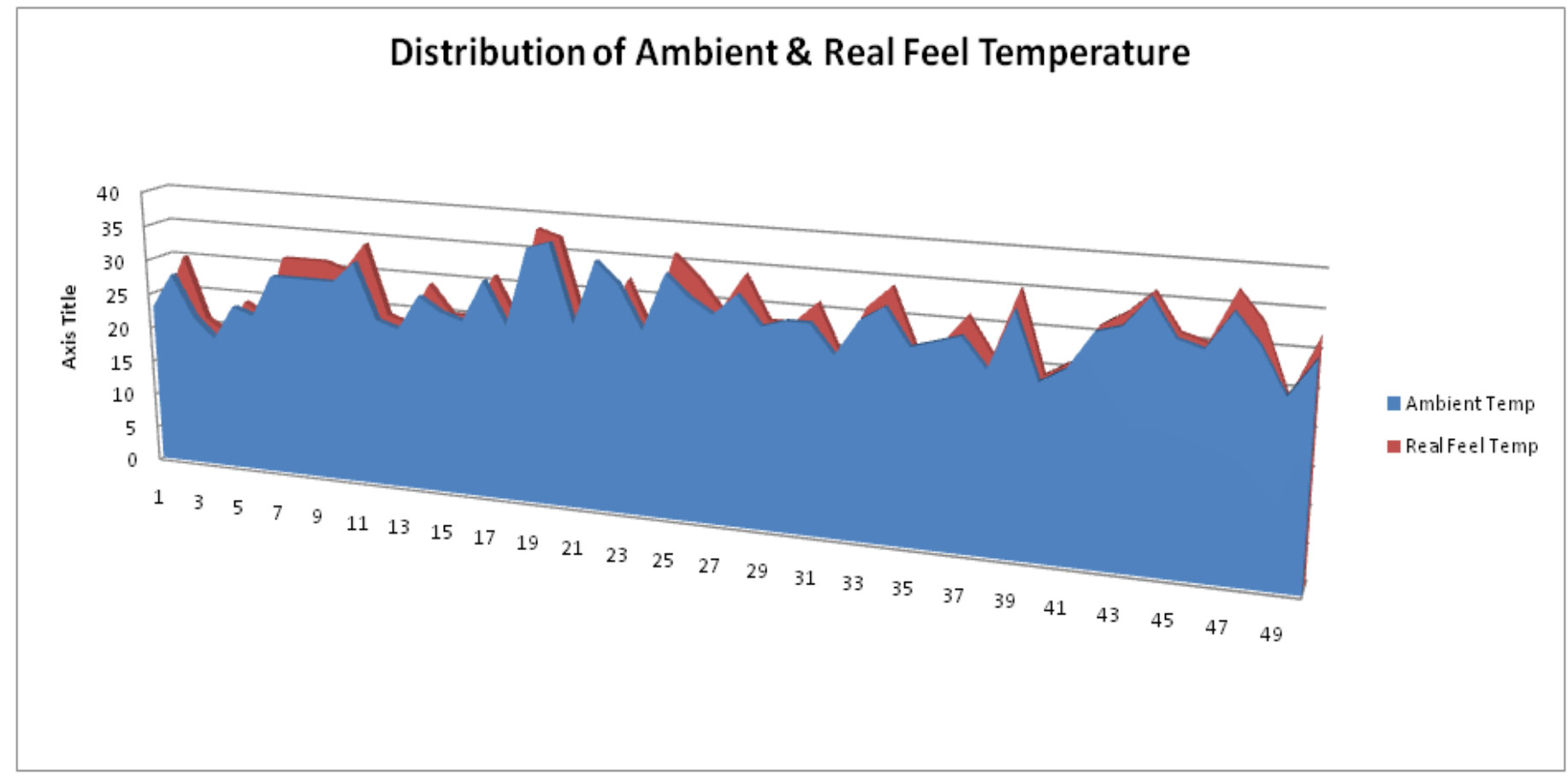




\section{Discussion}

Burns are among the oldest injuries that the man still suffers from. The treatment of burns is over 3,500 years old with the first direct evidence found in the cave painting of Neanderthal man. The earliest recorded account of treatment of burns is given in the Egyptian smith papyrus of 1500BC which advocated a salve of resins and honey. ${ }^{[2]}$

The Father of Plastic Surgery Sushruta (800BC) described the clinical symptoms of the burned patients especially the severe thirst and fever and has covered accidental burns in its four degrees, the effect of heat stroke, sun-stroke and frost-bite due to excessive cold and also the effect of lightening. He also advised debridement of severe burns. $^{[3]}$

Andrew M Munster(1970) became interested in measuring the quality of life after a severe burn in the when excisional surgery and other improvements had led to a dramatic decrease in mortality. ${ }^{[5]}$ First published in 1979 his burn specific health scale became the foundation for most modern studies in burn outcome. ${ }^{[3]}$

Although the value of early excision in very elderly patients remains an area of debate, progressive earlier surgical intervention has been successful in reducing overall burn mortality from sepsis in victims of major burn injury contributing to the significant increase in burn survival across all age groups. Mortality from other complication of major burns may decrease with early excision and grafting, ${ }^{[5]}$ decreasing stress, hypermetabolism and decreasing the overall bacterial load of such patients enable them to resist other complications better.

\section{Epidemiology}

The mortality of conservatively treated burn patients has remained high in India, even when the burn extent is less than 40\% TBSA. The epidemiological data with regard to burns patients in India is lacking \& most of the data are either hospital or city based.
The number of burn deaths in the United States has decreased from 15,000 in 1970 to 2000 in 2015. Over the same period the size of burn associated with a $50 \%$ survival rate has increased from $30 \%$ of the total body surface area (TBSA) to over $80 \%$ TBSA in otherwise healthy young adults. Hospital stay has been cut in half. $96 \%$ of patients admitted to burn centers survive, and $80 \%$ of them return to their pre burn physical and social situation within a year of the injury. ${ }^{[4]}$

\section{Transfer of Heat through Skin}

Normally the temperature of the surface of the skin is lower than the temperature of the dermis, but if heat is to be transferred from the heat source through the skin, the temperature of the skin surface must raise above that of the dermis. Once the temperature of the skin surface is sufficiently raised, heat will flow towards the dermis and raise the temperature of the skin at different levels.

The rate of transfer of heat depends on the heat capacity of the skin and on its thermal conductivity. The initial effect is a rapid uptake of the heat but after a time the skin becomes heatsaturated; the heat flow then depends on the simplified picture and is modified by various factors including the site, ${ }^{[14]}$ variations in the thickness of epidermis and the dermis, various physiological factors, such as the cooling effect of the blood flow and edema which may form during the burning episodes. ${ }^{[6,7]}$

For a given source of temperature, burning by conduction has at least a thousand times greater power to injure the epidermis than burning by radiation or by convection of relatively immobile air. ${ }^{[15]}$ This is because contact and conduction raises the surface temperature of the skin immediately to that of the source whilst radiation and convection raise the surface temperature relatively slowly. Heat may be brought to the skin by convection, radiation and conduction. Transfer by conduction has much greater power to heat the skin and produce burning, than that of transfer by other means. ${ }^{[16]}$ 


\section{Causes of Burns}

The major causes of burns are open flames, scalds, direct heat and burns of unknown origin. Burns from industrial accidents result primarily from molten metal's. Flammable volatile liquids and high voltage electricity are also important causes. Most severe burns tend to occur during the colder months and seventy five percent of incidents occur in homes. ${ }^{[17]}$ A major contribution to home fires is faulty building constructions with overcrowded and substandard conditions.

Stoves and heaters with burning wood, oil, charcoal, kerosene or gas are also primary contributors. Home accidents are fifteen times more common than burns in the industry. ${ }^{[10]}$

Table 3 Burn Severity Classification ${ }^{[7]}$

\begin{tabular}{|c|c|c|c|}
\hline Burn Severity & Children & Adults & Elderly \\
\hline \multirow[t]{2}{*}{ Minor } & $\cdot<10 \%$ TBSA & $\cdot<15 \%$ TBSA & $\cdot<10 \%$ TBSA \\
\hline & $\begin{array}{c}\text { - Full-thickness }<2 \% \\
\text { TBSA }\end{array}$ & $\begin{array}{c}\text { - Full-thickness }<2 \% \\
\text { TBSA }\end{array}$ & $\begin{array}{c}\text { - Full-thickness }<2 \% \\
\text { TBSA }\end{array}$ \\
\hline \multirow[t]{2}{*}{ Moderate } & $\cdot 10-20 \%$ TBSA & $\cdot 15-25 \%$ TBSA & $\cdot 10-20 \%$ TBSA \\
\hline & $\begin{array}{c}\text { - Full-thickness }<10 \% \\
\text { TBSA (non-critical } \\
\text { areas) }\end{array}$ & $\begin{array}{c}\cdot \text { Full-thickness } \\
<10 \% \text { TBSA (non- } \\
\text { critical areas) }\end{array}$ & $\begin{array}{c}\cdot \text { Full-thickness } \\
<10 \% \text { TBSA (non- } \\
\text { critical areas) }\end{array}$ \\
\hline \multirow[t]{4}{*}{ Severe } & $\cdot>20 \%$ TBSA & $\cdot>25 \%$ TBSA & $\cdot>20 \%$ TBSA \\
\hline & $\begin{array}{c}\text { - Full-thickness }>10 \% \\
\text { TBSA }\end{array}$ & $\begin{array}{c}\cdot \text { Full-thickness } \\
>10 \% \text { TBSA }\end{array}$ & $\begin{array}{c}\cdot \text { Full-thickness } \\
>10 \% \text { TBSA }\end{array}$ \\
\hline & $\begin{array}{l}\text { - Burns in critical } \\
\text { areas* }\end{array}$ & $\begin{array}{l}\text { - Burns in critical } \\
\text { areas* }\end{array}$ & $\begin{array}{c}\text { - Burns in critical } \\
\text { areas* }\end{array}$ \\
\hline & - Complicated burns*** & $\begin{array}{l}\text { - Complicated } \\
\text { burns*** }\end{array}$ & \\
\hline
\end{tabular}

\section{Causes of Death associated with burn: ${ }^{[18]}$}

\section{Immediate Causes}

a) Primary (neurogenic) shock: Occurs instantaneously from fear or inhibition from severe pain resulting in vaso-vagal shock or reflex cardiac arrest.

b) Secondary shock: If the patient survives from primary shock, serum loss from burnt area and consequent depletion of blood volume.

c) Suffocation: Apart from the actual burning, death may occur from asphyxia (suffocation) due to inhalation of the smoke, containing $\mathrm{CO} 2, \mathrm{CO}$ and other products of combustion.

d) Accidents or injuries: Accidental injuries from falling structures while trying to escape from the spot.

\section{Delayed Causes}

a) Toxaemia: Due to absorption of various metabolites from burnt tissue may persist up to 34 days.

b) Sepsis: The chief danger to life is the occurrence of sepsis in burns area and intercurrent disease especially of respiratory system. Sepsis is the most important factor in deaths occurring 4 to 5 days or longer after burning.

c) Biochemical Disturbances: These may occur secondary to fluid loss and destruction of tissue e.g., $\mathrm{K}+$ increase occurs initially, $\mathrm{Na}+$ loss, $\mathrm{Cl}++$ loss and hypoproteinemia are the common biochemical disturbances due to burn injury.

d) Acute renal failure

e) Gastrointestinal disturbances: Acute duodenal ulceration (Curling's ulcer), dilatation of 
stomach and severe hemorrhage occasionally develop in 1-2 weeks, after severe burns.

f) Other complications: Pulmonary embolism, fat embolism, thrombosis due to extensive tissue damage and immobility for longer period.

Tetanus, gangrene, erysipelas, is the other complications supparative discharges lasting for several weeks may lead to amyloidosis and exhaustation due to prolonged starvation

The Effect of Real Feel and Ambient Temperatures on the Mortality Rate of Burns Patients in a setup of Surgical wards of Government General Hospital, Guntur is studied with Daily Temperature recordings by Accu Weather App.

A total of 120 burn deaths of which 50 burns deaths caused due to Mixed Thermal Burns in surgical wards of GGH, Guntur.

Its an Observational Study carried between Jan 2017- Dec 2018. burns cases who stayed in hospital for more than $72 \mathrm{hrs}$ have been followed up. Charts have been plotted between Age, Sex distribution among Mixed Thermal Burns

Age wise distribution of Mixed Thermal Burns shows Mortality due Burns is more common in age group of 20-30 years both in Male \& Female Burns But studies show mortality is more common among extremes of age which i omitted in my study as age less than $12 \mathrm{i}$ have not included and age more than 60 case very less in my study.

Sex wise distribution is studied and found that Mixed thermal burns are more common in Female due to High Suicidal/Homicidal tendency and among the affected mortality is high in Females

The Effect of Ambient or Atmospheric Temperature on Burns is related to many factors including wind speed, humidity so it has to be studied along with real feel temperature which is the person feels to the body and it has no effect on the mortality alone as many factors will contribute to mortality like infections, hydration, concomitant diseases. So there will be no effect of Ambient \& Real Feel Temperature on the Mortality of Burns Patients

\section{Conclusion}

The conclusion of our study is that there is no effect of Ambient and Real Feel Temperatures on the mortality of Burns patients as such. Taking into study of 50 cases of mixed thermal burns admitted in Government General Hospital, Guntur over a period of 2 years between January 2017 to December 2018.

\section{References}

1. Gorea RK et al. Deaths due to thermal injury - an autopsy study. IJFS. 1990; 4.

2. Dalbir Singh et al. Recent trends in mortality in North-west India and its preventive aspects. TAFM. 1997; 19(4).

3. Agarwal BBL. Study of fatal cases of burns in South Zone. Delhi Punjab Medical Journal. 1971; 28: 451-58.

4. Jairaman V et al. Burns in Madras, India: An analysis of 1368 patients in one year. Burns. Aug 1993; 19(4): 339-44.

5. Still JM Jr., Law EJ, Primary excision of burn wound. Clin Plastic Surgery 2000 Jan 27(1); 23-47.

6. Cartotto RC, Innes M, Musgrave MA, et al: How well does the Parkland formula estimate actual fluid resuscitation $\mathbf{J}$ Burn Care Rehabil 23:258-265.

7. Mann R, Heimbach D: Prognosis and treatment of burns. West J Med 165:215 220, 1996.

8. Muller M, Herndon D: The challenge of burns. Lancet 343:216 - 220, 1994

9. Hanumadas, Ramakrishna. The Art And Science Of Burn Wound Management

10. Robert E Barrow, David N. Herndon. History and treatment of burns. Total burn care 3 rd edition pg1.

11. Surajit Bhattacharya. Sushrutha- our proud heritage. Indian J Plast Surg 2009;42(2): 223-225.

12. Tam N. Pham, MD, Nicole S. Gibran. Thermal and Electrical Injuries. Surg Clin N Am 2007; 87: 185-206.

13. Baris Cakir and Berrak C. Yegen. Systemic response to burn injury. Turk $\mathbf{J}$ Med Sci 2004;34:215-226. 
14. Bhattacharya S. Sushrutha - our proud heritage. Indian J Plastic Surgery 2009; 42:223-5

15. Underhill FP. The significance of anhydremia in extensive surface burns. JAMA. 1930; 95: 852-57.

16. Schwartz F. Charles. Brunicardi, Schwartz's textbook of surgery 10 th edition Burns ch 7: 190-124.

17. Marshall Jr WG, Dimick AR .The natural histology of major burns with multiple subsystem failure. J Trauma 1983; 23: 102-5.

18. Guyton, A. C.; Hall, J. E. (2006). Textbook of Medical Physiology. Elsevier Saunders. p. 464.

19. Bailey \& Love Text Book of Surgery 27 th Edn Burns Ch.6 P 610-635.

20. Sabiston 20 th Edn Burn care \& Management Ch 8 P 717-812. 